\title{
Study of an ADS Loaded with Thorium and Reprocessed Fuel
}

\author{
Graiciany de Paula Barros, ${ }^{1,2}$ Claubia Pereira,, ${ }^{1,2}$ \\ Maria A. F. Veloso, ${ }^{1,2}$ and Antonella L. Costa ${ }^{1,2}$ \\ ${ }^{1}$ Departamento de Engenharia Nuclear (DEN), Universidade Federal de Minas Gerais (UFMG), \\ Avenida Antonio Carlos 6627 Campus Pampulha, 31270-901 Belo Horizonte, MG, Brazil \\ ${ }_{2}^{2}$ Instituto Nacional de Ciências e Tecnologia de Reatores Nucleares Inovadores/CNPq Rede Nacional de Fusão/FINEP, Brazil
}

Correspondence should be addressed to Claubia Pereira, claubia@nuclear.ufmg.br

Received 15 November 2011; Revised 13 February 2012; Accepted 14 February 2012

Academic Editor: Alberto Talamo

Copyright (C) 2012 Graiciany de Paula Barros et al. This is an open access article distributed under the Creative Commons Attribution License, which permits unrestricted use, distribution, and reproduction in any medium, provided the original work is properly cited.

\begin{abstract}
Accelerator-driven systems (ADSs) are investigated for long-lived fission product transmutation and fuel regeneration. The aim of this paper is to investigate the nuclear fuel evolution and the neutronic parameters of a lead-cooled accelerator-driven system used for fuel breeding. The fuel used in some fuel rods was ${ }^{232} \mathrm{ThO}_{2}$ for ${ }^{233} \mathrm{U}$ production. In the other fuel rods was used a mixture based upon $\mathrm{Pu}-\mathrm{MA}$, removed from PWR-spent fuel, reprocessed by GANEX, and finally spiked with thorium or depleted uranium. The use of reprocessed fuel ensured the use of ${ }^{232} \mathrm{ThO}_{2}$ without the initial requirement of ${ }^{233} \mathrm{U}$ enrichment. In this paper was used the Monte Carlo code MCNPX 2.6.0 that presents the depletion/burnup capability, combining an ADS source and kcode-mode (for criticality calculations). The multiplication factor $\left(k_{\text {eff }}\right)$ evolution, the neutron energy spectra in the core at BOL, and the nuclear fuel evolution during the burnup were evaluated. The results indicated that the combined use of ${ }^{232} \mathrm{ThO}_{2}$ and reprocessed fuel allowed ${ }^{233} \mathrm{U}$ production without the initial requirement of ${ }^{233} \mathrm{U}$ enrichment.
\end{abstract}

\section{Introduction}

In recent years great interest has been given to acceleratordriven systems (ADSs). This is mainly because of their inherent safety features, their waste transmutation potential, and their capability to breed the required ${ }^{233} \mathrm{U}$ when the thorium fuel is used. ADSs are useful for recycling of americium, curium, neptunium, and plutonium. A great number of works on the ADS and the relative neutronics have been reported in the scientific literature [1-7]. Pioneers in this revival have been Furukawa et al. [8], Bowman et al. $[9,10]$, and Rubbia et al. [11, 12]. Very similar idea was first presented almost 60 years ago [13]. In an accelerator-driven system, an accelerator is coupled to a subcritical core loaded with nuclear fuel. The particles accelerated are injected into a spallation target that produces neutrons, which are used in the subcritical core for the fission chain maintenance.

Both critical reactors and subcritical accelerator-driven systems are potential candidates as dedicated transmutation systems. Critical reactors, however, loaded with fuel containing large amounts of MA have safety problems caused by unfavorable reactivity coefficients and small delayed neutron fraction. Nevertheless, subcritical systems present criticality and safety advantages: they operate with a neutron source rate that can be increased to compensate for the negative reactivity or any variation during the operation. Therefore, research interest in spent nuclear fuel transmutation has focused on both accelerator-driven systems and fusiondriven systems. At DEN/UFMG we began about 2006 and some results were obtained [14-16]. In this work, the focuses are ${ }^{233} \mathrm{U}$ production and transuranic transmutation possibility in accelerator-driven systems.

The main characteristic of ADS (i.e., subcriticality) is particularly favorable and allows a maximum transmutation rate while operating in a safe manner. An advantage of accelerator-driven systems is that, since there is no criticality condition to satisfy, almost any fuel composition can be used in the system [17]. Moreover, ADS could transmute $99.9 \%$ of transuranics light-water-reactor- (LWR-) spent nuclear fuel [18].

Another fuel proposed for using in ADS is the thoriumbased fuel. There are many reasons for the resurgence of 
interest in the thorium fuel cycle nowadays. The thorium's abundance is about three times more than uranium abundance. Thorium-fueled reactor is also an attractive tool to produce long-term nuclear energy with low radiotoxicity waste [19]. The main issue verified in the usage of this fuel in subcritical systems is the need of initial enrichment $\left({ }^{233} \mathrm{U}\right)$, since the use of natural thorium $\left({ }^{232} \mathrm{Th}\right)$ is not feasible due to the very low values of achieved criticality.

Based on those questions, this work presents a preliminary study of ADS for simultaneous use of thorium fuel and reprocessed fuel. The simultaneous usage of thorium fuel and spent fuel allows one to get appropriate values of criticality without the need of enrichment of thorium and still can reduce radiotoxicity of spent fuel by transmutation. The proposal is the simulation of a core with some fuel elements of ${ }^{232} \mathrm{Th}$ and other elements based on fuel spent from LWRs. There was simulated a cylindrical core of $12.0 \mathrm{~m}^{3}$ filled with a hexagonal lattice formed by 156 fuel rods, the fuel used in 36 rods was ${ }^{232} \mathrm{ThO}_{2}$, and the fuel used in the other 120 rods was reprocessed fuel spiked with thorium or depleted uranium. The reprocessed fuel was obtained from spent fuel discharged from the Brazilian PWR ANGRA-I, reprocessed by GANEX processes, and spiked with thorium or depleted uranium. Different percentages of $\mathrm{ThO}_{2}$ or $\mathrm{UO}_{2}$ were added to the reprocessed fuel and analyzed, as the use of only reprocessed fuel generates high criticality values. The neutron spectra were evaluated at BOL (Begin Of Life) and the criticality and the fuel evolution were investigated during ten years with the system operating at steady state, at $515 \mathrm{MW}$ of thermal power. During this time, the ${ }^{233} \mathrm{U}$ production and the reprocessed fuel evolution were quantified.

MCNPX 2.6.0 code [20] was used to simulate the geometrical and operational characteristics of the system. For the simulation there was used a combination of spallation source (external source-SDEF) and kcode-mode for the calculation of initial $k_{\text {eff }}$ and flux, describing in this way the real behavior of an ADS; that is, the initial criticality is the sum of neutrons produced by fission in the fuel and the neutrons produced by spallation in the target. During the burnup the code does not take into account the flux from external source, so the $k_{\text {eff }}$ and fuel evolution results obtained are just approximations. Moreover, the $k_{\text {eff }}$ results that were obtained during the burnup (kcode-mode) provide an insight of the necessary contribution of the external source during the operation period.

The isotopic composition of the reprocessed fuel used in this simulation was obtained using GANEX process (Group ActiNide EXtration) which is currently in testing phase [21]. The GANEX process developed by CEA for the reprocessing of Generation IV spent nuclear fuels is composed of two extraction cycles following the dissolution of the spent fuel. Once the uranium is selectively extracted from the dissolution solution by a monoamide solvent, the transuranic elements $(\mathrm{Np}, \mathrm{Pu}, \mathrm{Am}$, and $\mathrm{Cm})$ are separated from the fission products in a second cycle prior to the co-conversion step [22].

The GANEX first cycle recovers more than $99.99 \%$ of the total amount of uranium. In a second cycle neptunium, plutonium, americium, and curium are recovered altogether in one liquid flow (actinide product) and the losses of transuranics in the different outputs and in the solvent were estimated at a value lower than $0.5 \%$ (neptunium essentially) at the end of the test, corresponding to a recovery yield of actinides higher than $99.5 \%$. Nevertheless, the decontamination factors versus some lanthanides (especially $\mathrm{Nd}, \mathrm{Sm}$, and $\mathrm{Eu}$ ) were much lower than expected and the mass of lanthanides in the actinide product was around 5\% at the end [23].

\section{Methodology}

2.1. Computational Tool. The MCNPX 2.6.0 code was used to simulate the geometrical and operational characteristics of the system. Such version is quite interesting for the ADS evaluation because it describes the nuclear fuel evolution during the operation. For the calculation of the initial $k_{\text {eff }}$ and flux there was used a combination of spallation source (external source-SDEF) and kcode-mode. The code does not take into account the flux from external source during the burnup, so the results obtained are just approximations.

The depletion/burnup capability is based on CINDER90. MCNPX depletion is a linked process involving steady-state flux calculations by MCNPX and nuclide depletion calculations by CINDER90. The code runs a steady-state calculation to determine the system eigenvalue, 63-group fluxes, energy-integrated reaction rates, fission multiplicity, and recoverable energy per fission ( $Q$ values). CINDER90 then takes those MCNPX-generated values and performs the depletion calculation to generate new number densities for the next time step. MCNPX takes these new number densities and generates another set of fluxes and reaction rates. The process repeats itself until after the final time step specified by the user [24].

2.2. System Parameters. Figures 1 and 2 show schematic views of the simulated ADS. The basic geometry includes the spallation target, a subcritical core, and the reflector. The accelerator tube has a radius of $1.5 \mathrm{~cm}$, and the axial position is in the center of the target. The spallation source is represented by a neutrons source with a spectrum characteristic of spallation reactions. Such spectrum was generated, in a previous simulation, using a beam of $1-\mathrm{GeV}$ protons with a parabolic spatial profile. There was used Bertini intranuclear cascade model for the transport of protons, neutrons, and charged pions. The parameters of this simulation were described in [15].

Due to its high neutron yield by spallation reactions there was used lead as spallation target. The Pb cylindrical target has $9.5 \mathrm{~cm}$ radius and $39 \mathrm{~cm}$ height. Lead was also used as coolant and as reflector. The use of lead as coolant offers many advantages like convective cooling, passive safety and small neutron absorption cross section [25].

Another advantage of the lead coolant is that it is not a neutron moderator. This is important because the protactinium effect, which limits the achievable values of $k_{\text {eff }}$, is less severe for harder spectra. For solid fuels, systems without moderator and based on thorium, smaller values of capture 
TABLE 1: $\mathrm{UO}_{2}$ fuel composition after 33.000 MW d/T.

Actinides

Total weight fraction $=0.9785$

\begin{tabular}{|c|c|c|c|c|c|}
\hline Nuclide & Weight fraction & Nuclide & Weight fraction & Nuclide & Weight fraction \\
\hline${ }^{234} \mathrm{U}$ & $1.546 E-04$ & $\mathrm{H}$ & $1.525 E-06$ & $\mathrm{Ag}$ & $2.386 E-03$ \\
\hline${ }^{235} \mathrm{U}$ & $8.046 E-03$ & $\mathrm{Li}$ & $5.395 E-09$ & $\mathrm{Cd}$ & $3.267 E-03$ \\
\hline${ }^{236} \mathrm{U}$ & $4.113 E-03$ & $\mathrm{Be}$ & $4.384 E-09$ & In & $6.975 E-05$ \\
\hline${ }^{238} \mathrm{U}$ & $9.781 E-01$ & $\mathrm{C}$ & $7.707 E-10$ & Sn & $2.686 E-03$ \\
\hline${ }^{237} \mathrm{~Np}$ & $4.759 E-04$ & Co & $2.672 E-17$ & $\mathrm{Sb}$ & $8.428 E-04$ \\
\hline${ }^{238} \mathrm{Pu}$ & $1.851 E-04$ & $\mathrm{Ni}$ & $9.566 E-15$ & $\mathrm{Te}$ & $1.413 E-02$ \\
\hline${ }^{239} \mathrm{Pu}$ & $4.847 E-03$ & $\mathrm{Cu}$ & $8.460 E-14$ & I & $7.037 E-03$ \\
\hline${ }^{240} \mathrm{Pu}$ & $1.657 E-03$ & $\mathrm{Zn}$ & $1.186 E-09$ & $\mathrm{Xe}$ & $1.527 E-01$ \\
\hline${ }^{241} \mathrm{Pu}$ & $1.558 E-03$ & $\mathrm{Ga}$ & $6.593 E-10$ & Cs & $8.153 E-02$ \\
\hline${ }^{242} \mathrm{Pu}$ & $5.888 E-04$ & $\mathrm{Ge}$ & $1.929 E-05$ & $\mathrm{Ba}$ & $4.294 E-02$ \\
\hline${ }^{243} \mathrm{Am}$ & $1.126 E-04$ & As & $5.897 E-06$ & $\mathrm{La}$ & $3.566 E-02$ \\
\hline Others & $1.620 E-04$ & Se & $1.635 E-03$ & $\mathrm{Ce}$ & $7.546 E-02$ \\
\hline & $0 E+00$ & $\mathrm{Br}$ & $6.294 E-04$ & $\operatorname{Pr}$ & $3.211 E-02$ \\
\hline & s" include: & $\mathrm{Kr}$ & $1.058 E-02$ & $\mathrm{Nd}$ & $1.120 E-01$ \\
\hline${ }^{4} \mathrm{He}$ & $1.202 E-06$ & $\mathrm{Rb}$ & $9.934 E-03$ & $\mathrm{Pm}$ & $3.342 E-03$ \\
\hline${ }^{230} \mathrm{Th}$ & $3.407 E-09$ & $\mathrm{Sr}$ & $2.512 E-02$ & $\mathrm{Sm}$ & $2.246 E-02$ \\
\hline${ }^{233} \mathrm{U}$ & $2.069 E-09$ & $\mathrm{Y}$ & $1.339 E-02$ & $\mathrm{Eu}$ & $4.776 E-03$ \\
\hline${ }^{237} \mathrm{U}$ & $5.860 E-06$ & $\mathrm{Zr}$ & $1.031 E-01$ & Gd & $2.583 E-03$ \\
\hline${ }^{238} \mathrm{~Np}$ & $7.797 E-07$ & $\mathrm{Nb}$ & $6.179 E-04$ & $\mathrm{~Tb}$ & $8.146 E-05$ \\
\hline${ }^{239} \mathrm{~Np}$ & $4.923 E-05$ & Mo & $9.596 E-02$ & Dy & $4.039 E-05$ \\
\hline${ }^{241} \mathrm{Am}$ & $8.292 E-05$ & Tc & $2.262 E-02$ & Ho & $4.368 E-06$ \\
\hline${ }^{242} \mathrm{Am}$ & $1.526 E-07$ & $\mathrm{Ru}$ & $6.843 E-02$ & Er & $1.724 E-06$ \\
\hline${ }^{242} \mathrm{Cm}$ & $2.582 E-05$ & $\mathrm{Rh}$ & $1.275 E-02$ & $\operatorname{Tm}$ & $1.812 E-09$ \\
\hline${ }^{244} \mathrm{Cm}$ & $2.960 E-05$ & $\mathrm{Pd}$ & $3.906 E-02$ & $\mathrm{Yb}$ & $3.676 E-10$ \\
\hline${ }^{245} \mathrm{Cm}$ & $1.030 E-06$ & \multicolumn{4}{|c|}{ Total $1.000 E+00$} \\
\hline
\end{tabular}

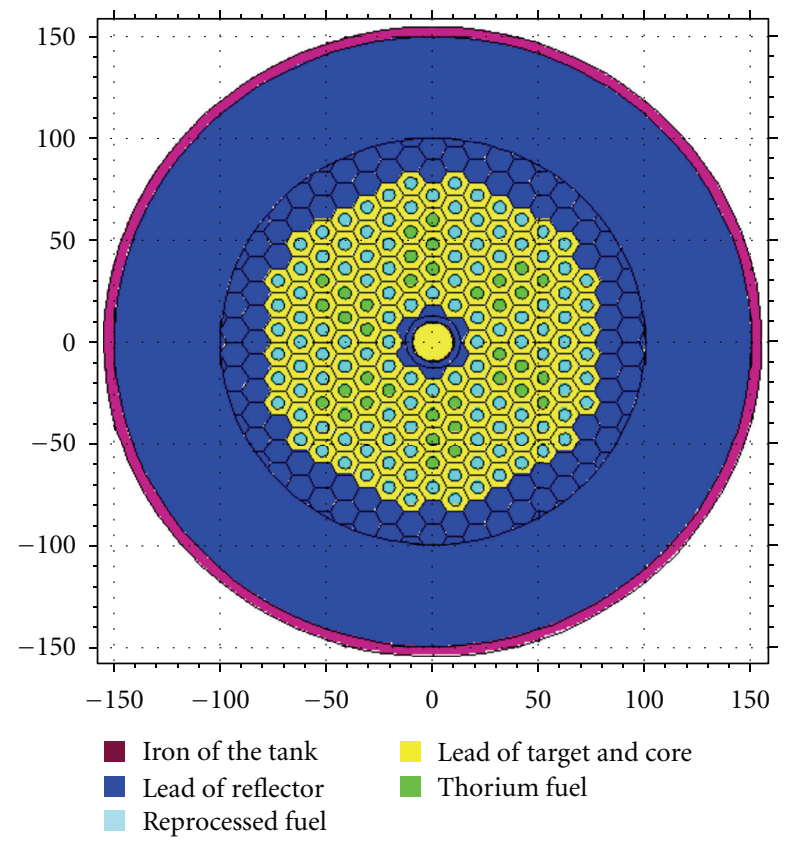

FIGURE 1: Horizontal cross section of the ADS simulated.
Fission Products

Total weight fraction $=0.0215$

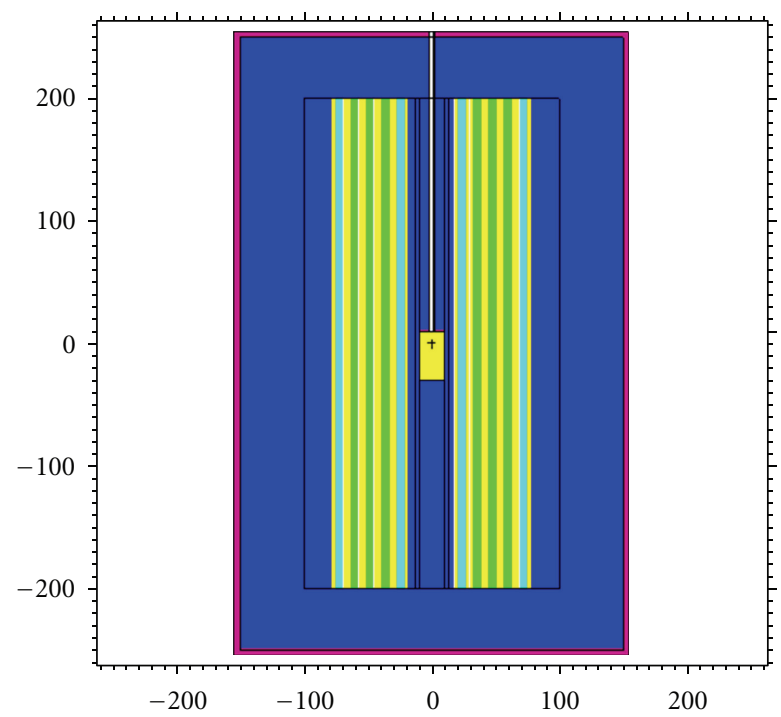

Figure 2: Vertical cross section of the ADS simulated.

cross sections of fission products will reduce the $k_{\text {eff }}$ variation and produce a hardening (shift to higher energies) in the neutron energy distribution. So, the inventory of ${ }^{233} \mathrm{U}$ is 
TABLE 2: Fuel composition (normalized) after reprocessing.

\begin{tabular}{lc}
\hline Actinides & Weight fraction \\
\hline${ }^{234} \mathrm{U}$ & $9.29 E-07$ \\
${ }^{235} \mathrm{U}$ & $4.83 E-05$ \\
${ }^{236} \mathrm{U}$ & $2.47 E-05$ \\
${ }^{238} \mathrm{U}$ & $5.88 E-03$ \\
${ }^{237} \mathrm{~Np}$ & $2.72 E-02$ \\
${ }^{238} \mathrm{Pu}$ & $1.11 E-02$ \\
${ }^{239} \mathrm{Pu}$ & $2.91 E-01$ \\
${ }^{240} \mathrm{Pu}$ & $9.95 E-02$ \\
${ }^{241} \mathrm{Pu}$ & $9.36 E-02$ \\
${ }^{242} \mathrm{Pu}$ & $3.54 E-02$ \\
${ }^{243} \mathrm{Am}$ & $6.76 E-03$ \\
${ }^{233} \mathrm{U}$ & $1.20 E-11$ \\
${ }^{237} \mathrm{U}$ & $3.52 E-08$ \\
${ }^{238} \mathrm{~Np}$ & $4.45 E-05$ \\
${ }^{239} \mathrm{~Np}$ & $2.81 E-03$ \\
${ }^{241} \mathrm{Am}$ & $4.98 E-03$ \\
${ }^{242} \mathrm{Am}$ & $9.17 E-06$ \\
${ }^{242} \mathrm{Cm}$ & $1.55 E-03$ \\
${ }^{244} \mathrm{Cm}$ & $1.78 E-03$ \\
${ }^{245} \mathrm{Cm}$ & $6.19 E-05$ \\
$\mathrm{Nd}$ & $3.36 E-01$ \\
$\mathrm{Sm}$ & $6.75 E-02$ \\
$\mathrm{Eu}$ & $1.43 E-02$ \\
\hline
\end{tabular}

much larger in fast reactors (about 7 times), with the associated larger breeding times and inventory radiotoxicity [26].

The simulated core is a cylinder of $12.0 \mathrm{~m}^{3}$ filled with a hexagonal lattice formed by 156 fuel rods. The fuel rod diameter is $6 \mathrm{~cm}$, the pitch is $12 \mathrm{~cm}$, and rod length is $400 \mathrm{~cm}$. The fuel used in 36 rods is ${ }^{232} \mathrm{ThO}_{2}$. The fuel used in the other 120 rods is spent fuel discharged from reactor ANGRAI, with initial enrichment of 3.1\%. This fuel was burned in ORIGEN 2.1 code [27] for three cycles, with the burnup of approximately $11.000 \mathrm{MW} \mathrm{d/t}$ in each cycle, following the ANGRA-I power historic of real cycles 1, 2, and 3. The composition of the spent fuel used is shown in Table 1 [28], after remaining 5 years in a cooling pool.

After cooling by five years, the spent nuclear was submitted to GANEX reprocessing and the isotopic composition after the reprocessing is presented in Table 2. The amount of uranium after the reprocessing is $0.01 \%$ of the total amount of uranium in the burned fuel. In terms of actinides, neptunium, plutonium, americium, and curium are recovered with a loss of only $0.5 \%$ (neptunium essentially). The lanthanides contamination in the reprocessed fuel is around $5 \%$. The isotopic composition presented in Table 2 was adjusted (with a computational program) for several percentages of thorium or depleted uranium added to the reprocessed fuel and the final composition $\left(\mathrm{ThO}_{2}\right.$ or $\mathrm{UO}_{2}+$ reprocessed fuel) was normalized. The ratio between the number of thorium fuel rods and reprocessed fuel rods and the positions of the thorium fuel rods were determined to maximize the amount

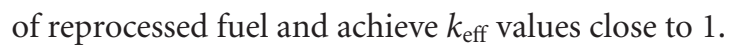

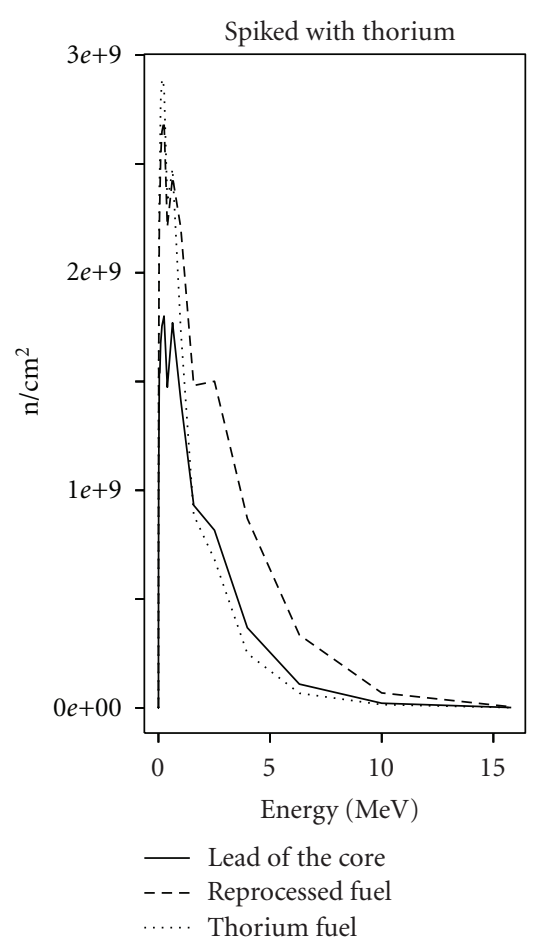

(a)

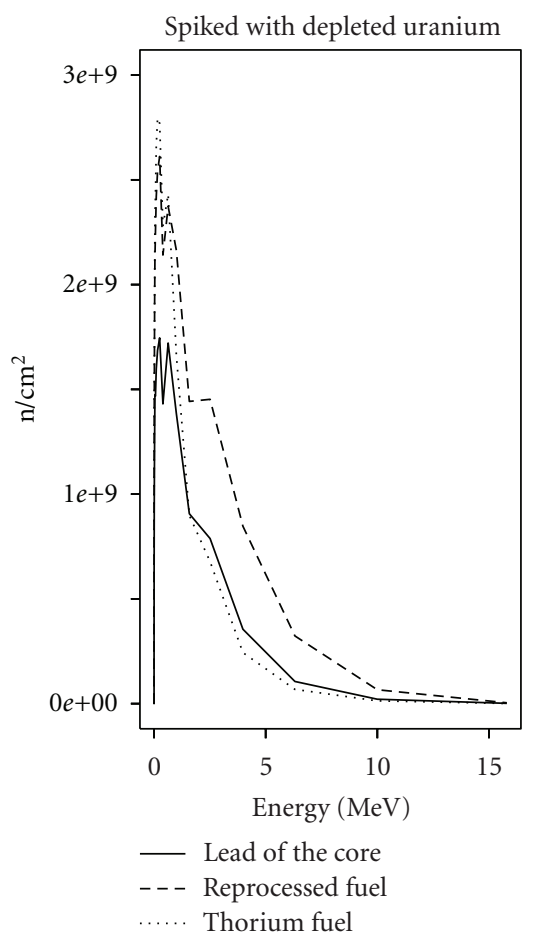

(b)

Figure 3: Neutron energy distributions in the (BOL).

The isotopic compositions used in the simulations with several percentages of thorium or depleted uranium added to the reprocessed fuel are shown in Tables 3 and 4 .

2.3. Calculational Procedure. For this simulation there was used a combination of ADS source (SDEF) and kcode-mode 
TABLE 3: Fuel composition (normalized) for the reprocessed fuels spiked with thorium.

\begin{tabular}{|c|c|c|c|}
\hline Actinides & $\begin{array}{l}\text { Weight fraction fuel spiked with } 60 \% \\
\text { of thorium }\end{array}$ & $\begin{array}{l}\text { Weight fraction fuel spiked with } 61 \% \\
\text { of thorium }\end{array}$ & $\begin{array}{l}\text { Weight fraction fuel spiked with } 62 \% \\
\text { of thorium }\end{array}$ \\
\hline${ }^{234} \mathrm{U}$ & $3.7145 E-007$ & $3.6216 E-007$ & $3.5287 E-007$ \\
\hline${ }^{235} \mathrm{U}$ & $1.9331 E-005$ & $1.8848 E-005$ & $1.8365 E-005$ \\
\hline${ }^{236} \mathrm{U}$ & $9.8820 E-006$ & $9.6349 E-006$ & $9.3879 E-006$ \\
\hline${ }^{238} \mathrm{U}$ & 0.0023500 & 0.0022913 & 0.0022325 \\
\hline${ }^{237} \mathrm{~Np}$ & 0.010862 & 0.010591 & 0.010319 \\
\hline${ }^{238} \mathrm{Pu}$ & 0.0044473 & 0.0043361 & 0.0042249 \\
\hline${ }^{239} \mathrm{Pu}$ & 0.11646 & 0.11354 & 0.11063 \\
\hline${ }^{240} \mathrm{Pu}$ & 0.039811 & 0.038816 & 0.037821 \\
\hline${ }^{241} \mathrm{Pu}$ & 0.037433 & 0.036497 & 0.035561 \\
\hline${ }^{242} \mathrm{Pu}$ & 0.014147 & 0.013793 & 0.013439 \\
\hline${ }^{243} \mathrm{Am}$ & 0.0027054 & 0.0026377 & 0.0025701 \\
\hline${ }^{233} \mathrm{U}$ & $4.8052 E-012$ & $4.6851 E-012$ & $4.5650 E-012$ \\
\hline${ }^{237} \mathrm{U}$ & $1.4079 E-008$ & $1.3727 E-008$ & $1.3375 E-008$ \\
\hline${ }^{238} \mathrm{~Np}$ & $1.7797 E-005$ & $1.7352 E-005$ & $1.6907 E-005$ \\
\hline${ }^{239} \mathrm{~Np}$ & 0.0011237 & 0.0010956 & 0.0010675 \\
\hline${ }^{241} \mathrm{Am}$ & 0.0019923 & 0.0019424 & 0.0018926 \\
\hline${ }^{242} \mathrm{Am}$ & $3.6664 E-006$ & $3.5747 E-006$ & $3.4831 E-006$ \\
\hline${ }^{242} \mathrm{Cm}$ & 0.00062036 & 0.00060485 & 0.00058934 \\
\hline${ }^{244} \mathrm{Cm}$ & 0.00071118 & 0.00069340 & 0.00067562 \\
\hline${ }^{245} \mathrm{Cm}$ & $2.4747 E-005$ & $2.4128 E-005$ & $2.3510 E-005$ \\
\hline $\mathrm{Nd}$ & 0.13455 & 0.13118 & 0.12782 \\
\hline $\mathrm{Sm}$ & 0.026981 & 0.026307 & 0.025632 \\
\hline $\mathrm{Eu}$ & 0.0057375 & 0.0055940 & 0.0054506 \\
\hline${ }^{232} \mathrm{Th}$ & 0.20000 & 0.20333 & 0.20667 \\
\hline $\mathrm{O}$ & 0.40000 & 0.40667 & 0.41333 \\
\hline
\end{tabular}

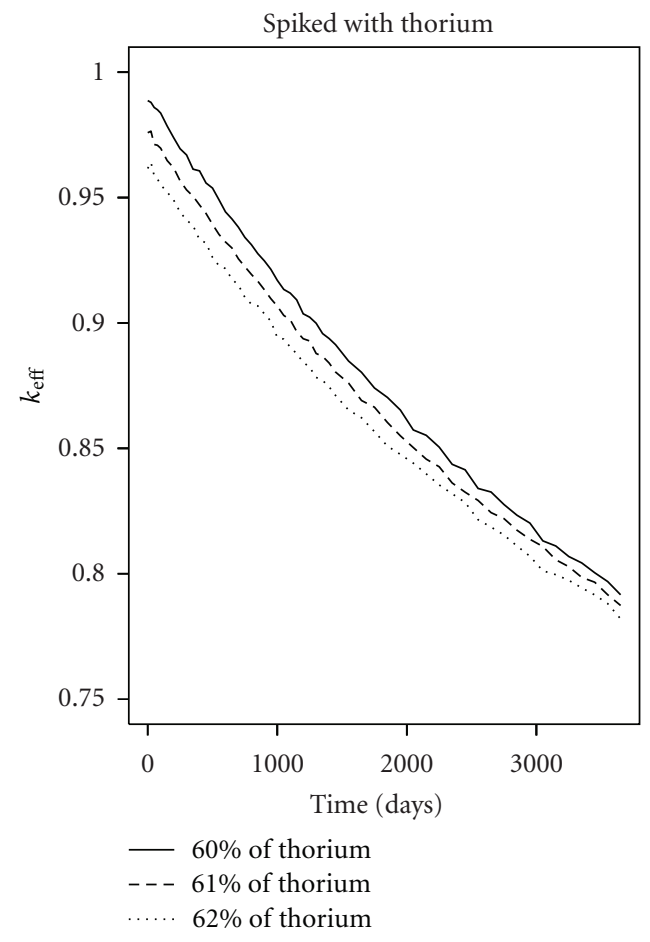

(a)

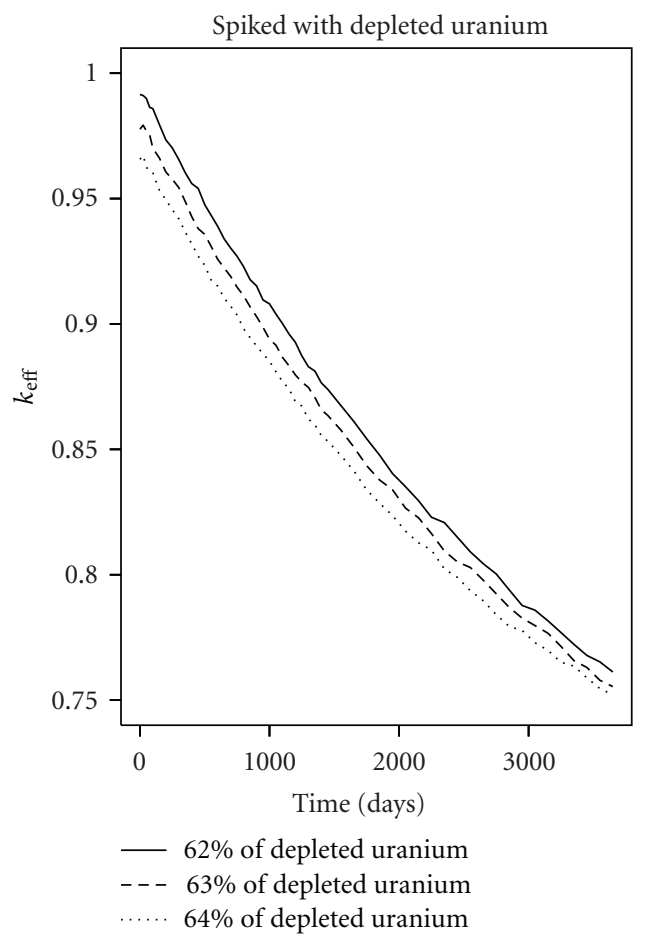

(b)

FIGURE 4: Multiplication factor $\left(k_{\text {eff }}\right)$ evolution. 
TABLE 4: Fuel composition (normalized) for the reprocessed fuels spiked with depleted uranium.

\begin{tabular}{|c|c|c|c|}
\hline Actinides & $\begin{array}{l}\text { Weight fraction fuel spiked with } 62 \% \\
\text { of depleted uranium }\end{array}$ & $\begin{array}{l}\text { Weight fraction fuel spiked with } 63 \% \\
\text { of depleted uranium }\end{array}$ & $\begin{array}{l}\text { Weight fraction fuel spiked with } 64 \% \\
\text { of depleted uranium }\end{array}$ \\
\hline${ }^{234} \mathrm{U}$ & $3.5287 E-007$ & $3.4359 E-007$ & $3.3430 E-007$ \\
\hline${ }^{235} \mathrm{U}$ & $1.8365 E-005$ & $1.7882 E-005$ & $1.7398 E-005$ \\
\hline${ }^{236} \mathrm{U}$ & $9.3879 E-006$ & $9.1408 E-006$ & $8.8938 E-006$ \\
\hline${ }^{238} \mathrm{U}$ & 0.0022325 & 0.0021738 & 0.0021150 \\
\hline${ }^{237} \mathrm{~Np}$ & 0.010319 & 0.010048 & 0.0097761 \\
\hline${ }^{238} \mathrm{Pu}$ & 0.0042249 & 0.0041137 & 0.0040025 \\
\hline${ }^{239} \mathrm{Pu}$ & 0.11063 & 0.10772 & 0.10481 \\
\hline${ }^{240} \mathrm{Pu}$ & 0.037821 & 0.036826 & 0.035830 \\
\hline${ }^{241} \mathrm{Pu}$ & 0.035561 & 0.034625 & 0.033690 \\
\hline${ }^{242} \mathrm{Pu}$ & 0.013439 & 0.013086 & 0.012732 \\
\hline${ }^{243} \mathrm{Am}$ & 0.0025701 & 0.0025025 & 0.0024348 \\
\hline${ }^{233} \mathrm{U}$ & $4.5650 E-012$ & $4.4449 E-012$ & $4.3247 E-012$ \\
\hline${ }^{237} \mathrm{U}$ & $1.3375 E-008$ & $1.3023 E-008$ & $1.2671 E-008$ \\
\hline${ }^{238} \mathrm{~Np}$ & $1.6907 E-005$ & $1.6462 E-005$ & $1.6017 E-005$ \\
\hline${ }^{239} \mathrm{~Np}$ & 0.0010675 & 0.0010394 & 0.0010113 \\
\hline${ }^{241} \mathrm{Am}$ & 0.0018926 & 0.0018428 & 0.0017930 \\
\hline${ }^{242} \mathrm{Am}$ & $3.4831 E-006$ & $3.3914 E-006$ & $3.2998 E-006$ \\
\hline${ }^{242} \mathrm{Cm}$ & 0.00058934 & 0.00057383 & 0.00055832 \\
\hline${ }^{244} \mathrm{Cm}$ & 0.00067562 & 0.00065784 & 0.00064006 \\
\hline${ }^{245} \mathrm{Cm}$ & $2.3510 E-005$ & $2.2891 E-005$ & $2.2272 E-005$ \\
\hline $\mathrm{Nd}$ & 0.12782 & 0.12446 & 0.12109 \\
\hline $\mathrm{Sm}$ & 0.025632 & 0.024958 & 0.024283 \\
\hline $\mathrm{Eu}$ & 0.0054506 & 0.0053072 & 0.0051637 \\
\hline${ }^{238} \mathrm{U}$ & 0.20625 & 0.20958 & 0.21291 \\
\hline${ }^{235} \mathrm{U}$ & 0.00041333 & 0.00042000 & 0.00042667 \\
\hline${ }^{234} \mathrm{U}$ & $2.0667 E-006$ & $2.1000 E-006$ & $2.1333 E-006$ \\
\hline $\mathrm{O}$ & 0.41333 & 0.42000 & 0.42667 \\
\hline
\end{tabular}

for calculation of initial $k_{\text {eff }}$ and flux. The SDEF source was positioned on the center of the target. The burnup calculations were performed in kcode-mode using 53 time steps; the total simulated time was 10 years and the thermal power of operation throughout this period was $515 \mathrm{MW} \mathrm{t}$. were performed simulations using reprocessed fuel spiked with thorium in different percentages and simulations using reprocessed fuel spiked with different percentages of depleted uranium.

\section{Results}

3.1. Neutronic Evaluation. In Figure 3 is shown the normalized neutron energy distribution (for the systems spiked with $62 \%$ of thorium and $62 \%$ of depleted uranium) in the BOL (beginning of life). Both spectra in the thorium fuel present their maximum around $150 \mathrm{keV}$ and around $250 \mathrm{keV}$ in the reprocessed fuel. Therefore, the reprocessed fuel neutron spectrum is harder than thorium fuel spectrum. That is result of the plutonium presence that emits fission neutrons with a harder spectrum. The spectra for the system loaded with fuel spiked with thorium are very similar to spectra for the fuel spiked with depleted uranium. The spectrum in the lead of the core (coolant) presents a similar neutrons energy distribution to fuel spectra, but the number of neutrons available in the fuel is larger due to neutron production by fission reactions.

Figure 4 shows the multiplication factor $\left(k_{\mathrm{eff}}\right)$ as a time function for the systems loaded with ${ }^{232} \mathrm{ThO}_{2} \quad(24$ rods) and reprocessed fuel (132 rods) spiked with thorium (Figure $4(\mathrm{a})$ ) and spiked with depleted uranium (Figure $4(\mathrm{~b})$ ). The percentages of thorium and depleted uranium in the reprocessed fuel were varied and the $k_{\text {eff }}$ values obtained are represented in Figure 4. The percentages of thorium or depleted uranium were chosen in such a way that the values for the initial $k_{\text {eff }}$ were close to 1 , since a large variability on those percentages could lead to considerably low initial $k_{\text {eff values. }}$

From Figure 4 can be observed that after some years of operation the decrease in the $k_{\text {eff }}$ value was smaller in the system which used reprocessed fuel spiked with thorium. That behavior indicates that the use of reprocessed fuel spiked with thorium allows an extension of the burnup without reloading fuel. 
For the same percentage of thorium and depleted uranium $(62 \%)$, the $k_{\text {eff }}$ values for the system spiked with depleted uranium ( $k_{\text {eff }}$ variation of 0.991 to 0.761 ) were significantly higher than these for the system spiked with thorium $\left(k_{\text {eff }}\right.$ variation of 0.964 to 0.782 ), but the decrease in the $k_{\text {eff }}$ for the system with depleted uranium was also higher.

The drop of the $k_{\text {eff }}$ value observed in two cases is mainly due to the increased poisoning caused by the accumulation of fission products having large neutron capture cross sections and, of course, the constant energy generation by the system.

3.2. Thorium Fuel Evolution. Figure 5 describes the ${ }^{232} \mathrm{Th}$, ${ }^{233} \mathrm{~Pa}$, and ${ }^{233} \mathrm{U}$ concentrations in the thorium fuel rods during the 10 years of operation for the systems spiked with $62 \%$ of thorium and $62 \%$ of depleted uranium. It can be verified that for the system spiked with thorium the concentration of the isotope ${ }^{232} \mathrm{Th}$ was reduced by about $17 \%(623 \mathrm{~kg})$, for the system spiked with depleted uranium that was about $18 \%(644 \mathrm{~kg})$. It is the result of the considerable capture cross section of that isotope, which allows the ${ }^{233} \mathrm{U}$ production. ${ }^{233} \mathrm{U}$ is formed when ${ }^{232} \mathrm{Th}$ captures a neutron, and it soon undergoes two beta decays:

$$
{ }^{232} \mathrm{Th}+n \longrightarrow{ }^{233} \mathrm{Th} \stackrel{\beta-}{\longrightarrow}{ }^{233} \mathrm{~Pa} \stackrel{\beta-}{\longrightarrow}{ }^{233} \mathrm{U}
$$

A relevant question in the neutron spectrum choice is the protactinium effect. Protactinium captures neutrons (due to its large capture cross section) and, thus, decreases the reactivity and fuel regeneration. From Figure 5 can be observed that this isotope is formed in small scale in both systems. Furthermore, the protactinium effect is less severe for harder spectra like that.

Figure 5 also presents the ${ }^{233} \mathrm{U}$ concentration during the burnup, which is formed in large scale $(\sim 282 \mathrm{~kg})$ for the system with reprocessed fuel spiked with thorium and $(\sim 284 \mathrm{~kg})$ for the system spiked with depleted uranium. That ${ }^{233} \mathrm{U}$ production was due to ${ }^{232} \mathrm{Th}$ regeneration. Then these results show that the combined use of ${ }^{232} \mathrm{ThO}_{2}$ and reprocessed fuel allowed ${ }^{233} \mathrm{U}$ production without the initial requirement of ${ }^{233} \mathrm{U}$ enrichment.

3.3. Reprocessed Fuel Evolution. The long-term potential radiotoxicity of the spent nuclear fuel is mainly associated with transuranics (TRU) particularly $\mathrm{Pu}$ and MA: Am, Cm, and Np. These constitute a significant radiological source term over a very long period within a spent fuel [29]. Figures 6-9 show the concentration of those isotopes during the burnup.

In a standard uranium-uranium $\left({ }^{235} \mathrm{U}_{x},{ }^{238} \mathrm{U}_{1-x}\right)$ fuel used in nuclear reactors, the isotope of neptunium, ${ }^{237} \mathrm{~Np}$, originates from ${ }^{235} \mathrm{U}$, and the isotopes of americium, ${ }^{241} \mathrm{Am}$ and ${ }^{243} \mathrm{Am}$, and curium, ${ }^{242} \mathrm{Cm},{ }^{244} \mathrm{Cm}$, and ${ }^{245} \mathrm{Cm}$, from ${ }^{238} \mathrm{U}$ as a result of nuclear reactions [30].

Plutonium is the major element for radiotoxicity and mass in the storage [31]. ${ }^{238} \mathrm{Pu}$, which is generated from ${ }^{237} \mathrm{~Np}$, was produced in large scale in the system simulated (Figure 6), while ${ }^{239} \mathrm{Pu}$ and ${ }^{241} \mathrm{Pu}$ mass were reduced mainly due to fission reactions. ${ }^{240} \mathrm{Pu}$ is formed when ${ }^{239} \mathrm{Pu}$ captures

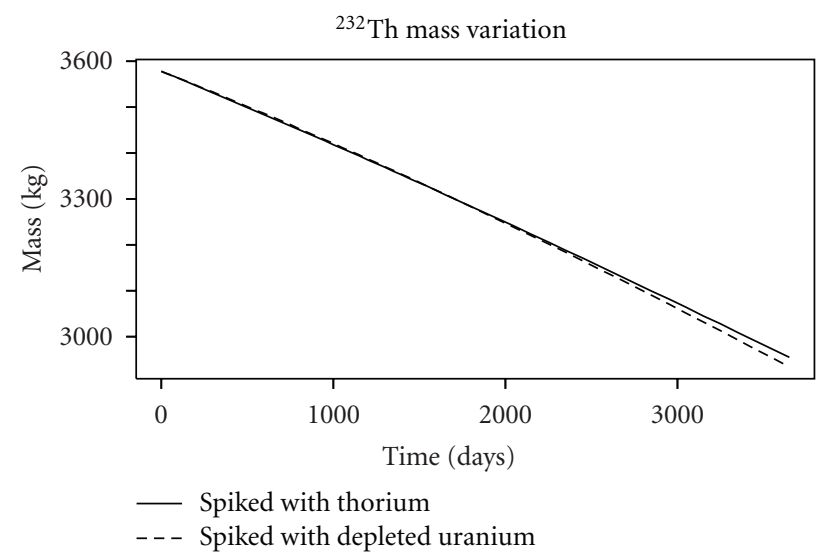

(a)

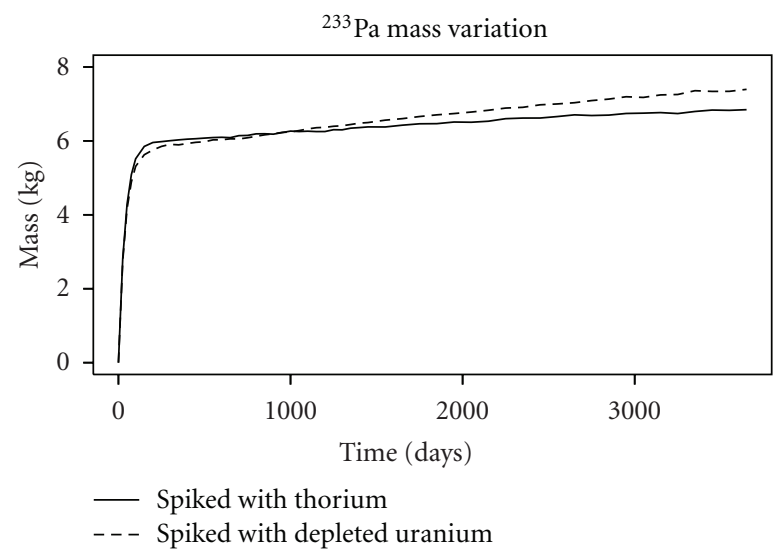

(b)

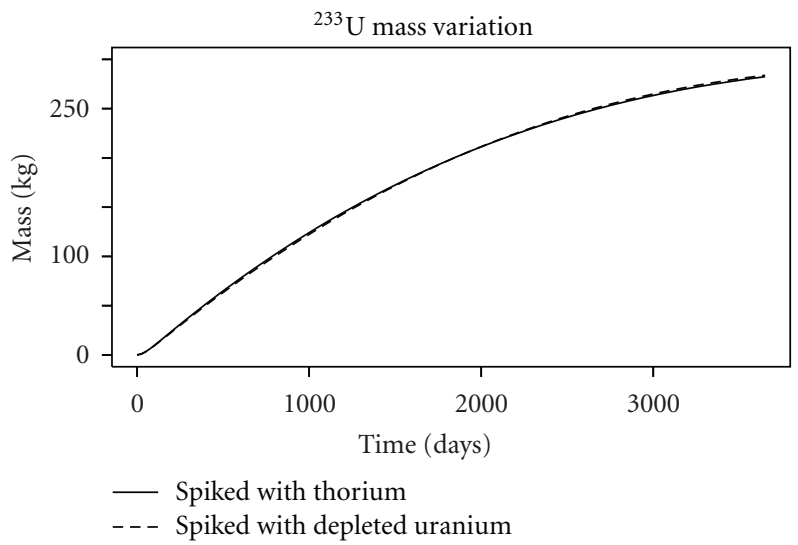

(c)

FIgURE 5: ${ }^{232} \mathrm{Th},{ }^{233} \mathrm{~Pa}$, and ${ }^{233} \mathrm{U}$ mass variations.

a neutron that justifies the high production of that isotope due to the reduced in ${ }^{239} \mathrm{Pu} .{ }^{242} \mathrm{Pu}$ was formed in small scale. The greater plutonium production in the system spiked with depleted uranium was due to the greater uranium availability in this system that allows the ${ }^{237} \mathrm{~Np}$ formation and consequently plutonium production.

Long-lived isotopes of americium produced are ${ }^{241} \mathrm{Am}$ and ${ }^{243} \mathrm{Am}$. Americium is produced by $\beta$-decay of ${ }^{241} \mathrm{Pu}\left({ }^{241} \mathrm{Pu} \rightarrow{ }^{241} \mathrm{Am}\right)$ and $(n, \gamma)$ reaction of 


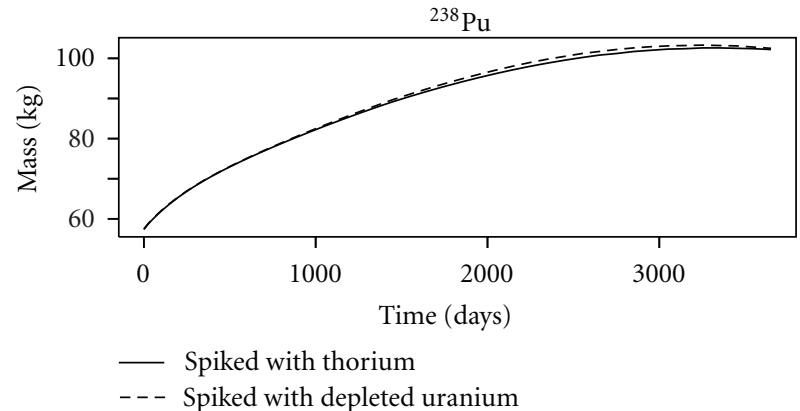

(a)

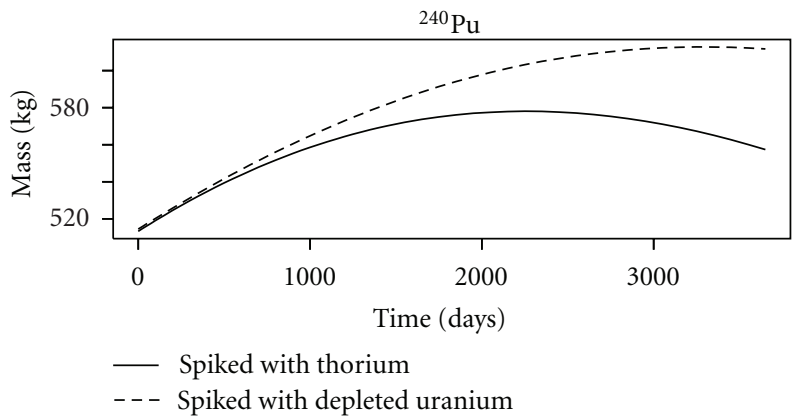

(c)

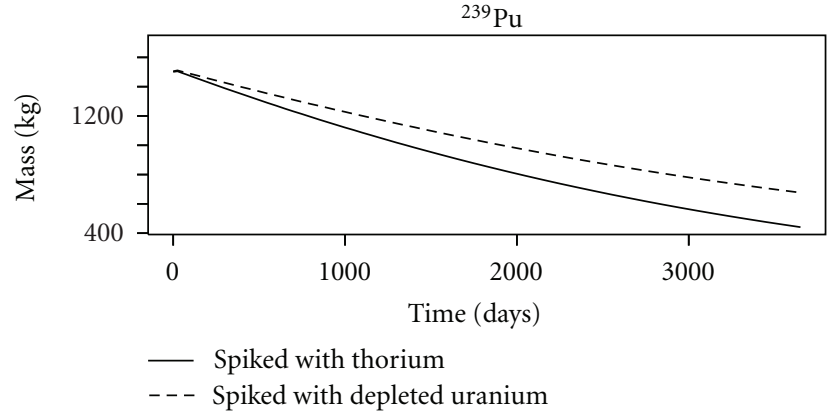

(b)

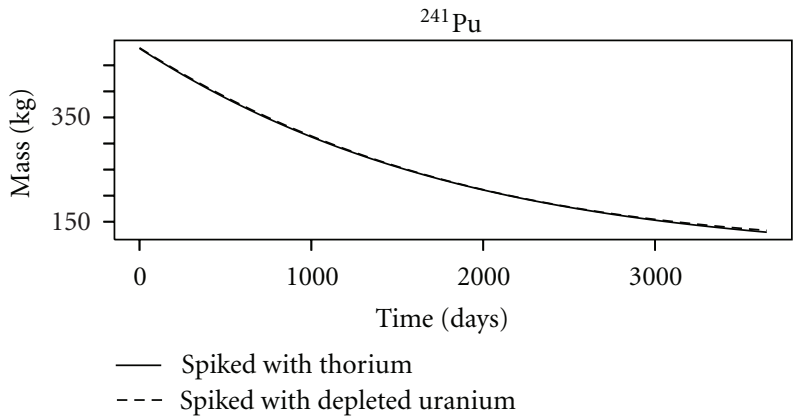

(d)

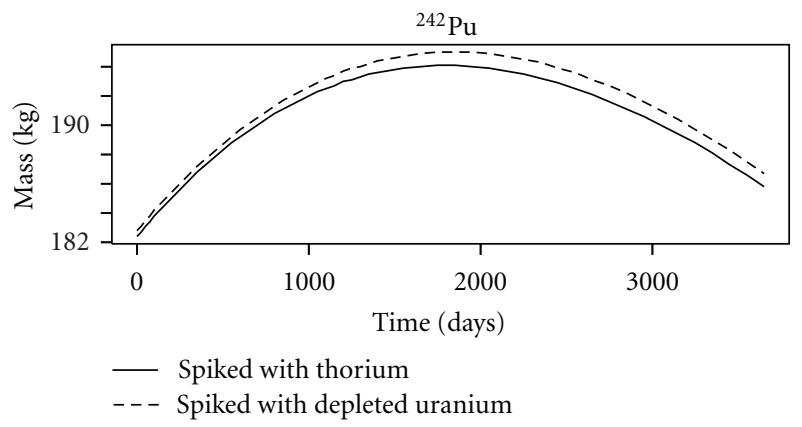

(e)

FIGURE 6: Plutonium mass variations.

${ }^{242} \mathrm{Pu}\left({ }^{242} \mathrm{Pu} \rightarrow{ }^{243} \mathrm{Am}\right)$ during the operation. The mass variation of americium is showed in Figure 7; the difference between the americium productions in the two cases was very small.

Long-lived isotopes of curium produced are ${ }^{242} \mathrm{Cm}$, ${ }^{244} \mathrm{Cm}$, and ${ }^{245} \mathrm{Cm}$. At that, isotope ${ }^{242} \mathrm{Cm}$ has a relatively short lifetime justifying its low production (Figure 8 ). The radioactive decay of ${ }^{242} \mathrm{Cm}$ proceeds as follows:

$$
\begin{aligned}
& { }^{242} \mathrm{Cm}\left(T_{1 / 2}=163 \text { days; } \alpha\right) \\
& \longrightarrow{ }^{238} \mathrm{Pu}\left(T_{1 / 2}=87.7 \text { years; } \alpha\right) \\
& \longrightarrow{ }^{234} \mathrm{U}\left(T_{1 / 2}=2.46 \times 10^{5} \text { years; } \alpha\right) .
\end{aligned}
$$

Curium is the most intensely radioactive of the actinides for both neutron emission and $\alpha$-activity [32]. The most abundant of its isotopes is ${ }^{244} \mathrm{Cm}$, which decays with a half-life of
18 years to form ${ }^{240} \mathrm{Pu}$. Radioactive decay of ${ }^{244} \mathrm{Cm}$ occurs as follows:

$$
\begin{aligned}
& { }^{244} \mathrm{Cm}\left(T_{1 / 2}=18.1 \text { years; } \alpha\right) \\
& \longrightarrow{ }^{240} \mathrm{Pu}\left(T_{1 / 2}=6.56 \times 10^{3} \text { years; } \alpha\right) .
\end{aligned}
$$

The radioactive decay of ${ }^{245} \mathrm{Cm}$ to the nearest long-lived daughter nucleus proceeds as follows:

$$
\begin{aligned}
& { }^{245} \mathrm{Cm}\left(T_{1 / 2}=8.5 \times 10^{3} \text { years; } \alpha\right) \\
& \longrightarrow{ }^{241} \mathrm{Pu}\left(T_{1 / 2}=14.4 \text { years; } \beta\right) \\
& \longrightarrow{ }^{241} \mathrm{Am}\left(T_{1 / 2}=4.33 \times 10^{2} \text { years; } \alpha\right) .
\end{aligned}
$$

From Figure 8 can be observed increase in the masses of ${ }^{245} \mathrm{Cm}$ and ${ }^{244} \mathrm{Cm}$. At long-term burnup of plutonium, there is the increase of radiotoxicity determined by accumulation of ${ }^{244} \mathrm{Cm}$. The burnup of plutonium should be done by much 




(a)



(b)

Figure 7: Americium mass variations.



Spiked with thorium

- - Spiked with depleted uranium

(a)

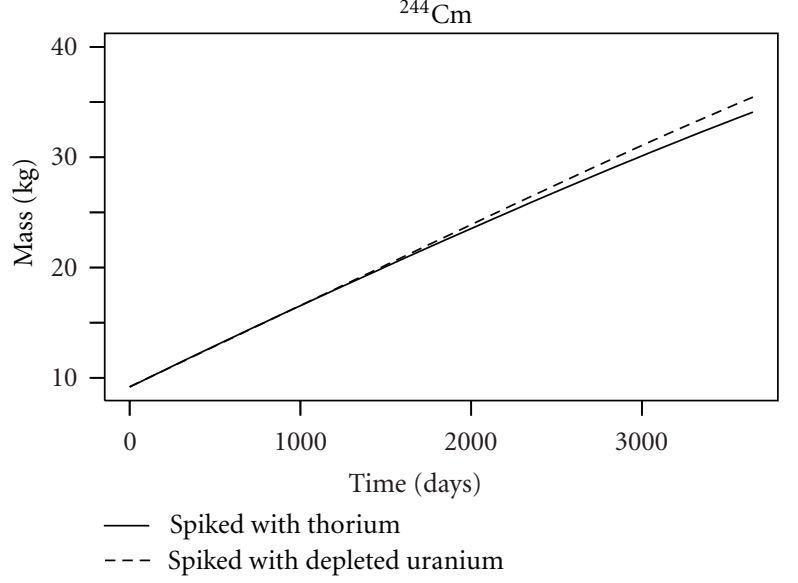

(b)

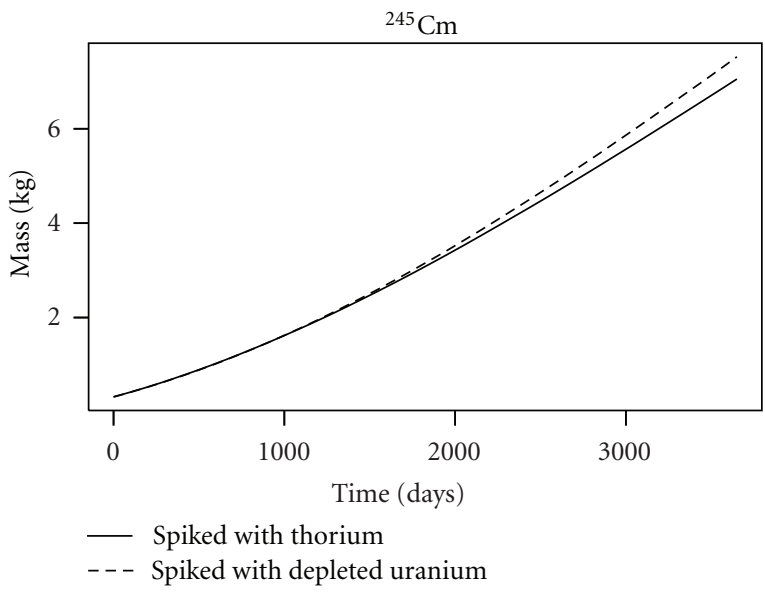

(c)

FIGURE 8: Curium mass variations. 




(a)

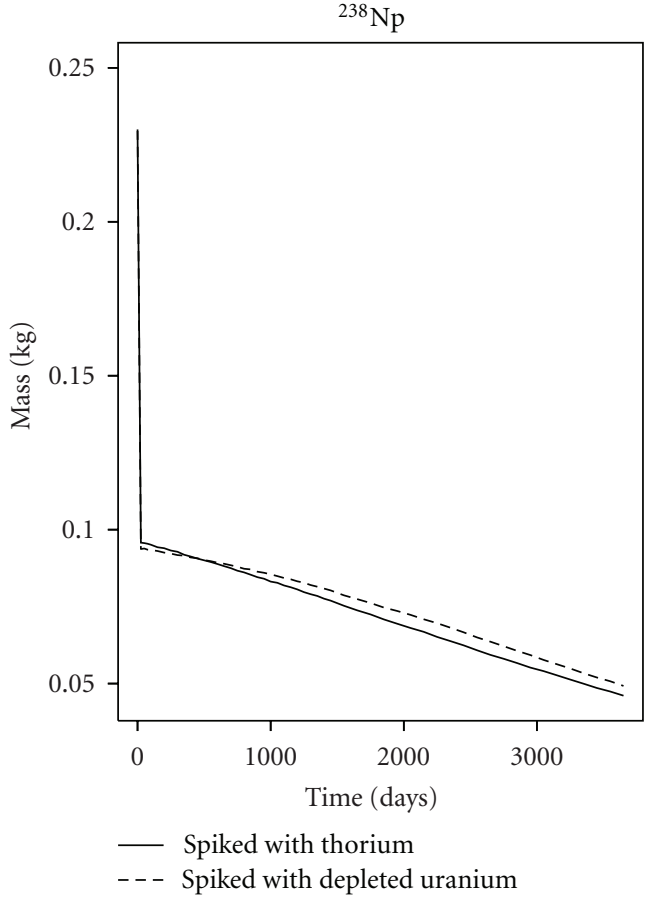

(b)

Figure 9: Neptunium mass variations.

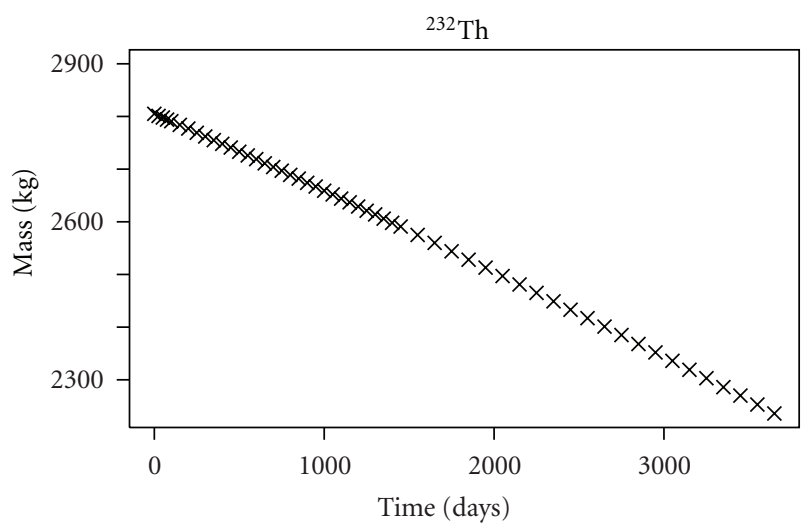

$\times$ Spiked with thorium

(a)

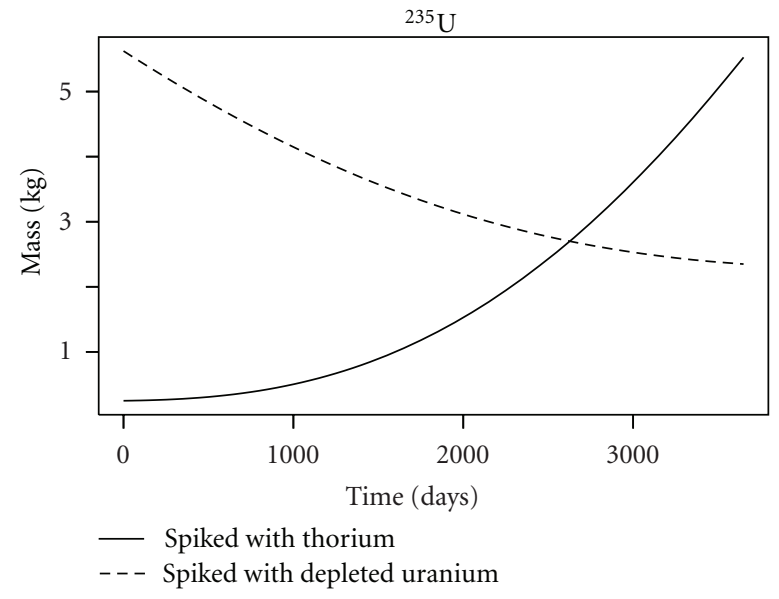

(c)

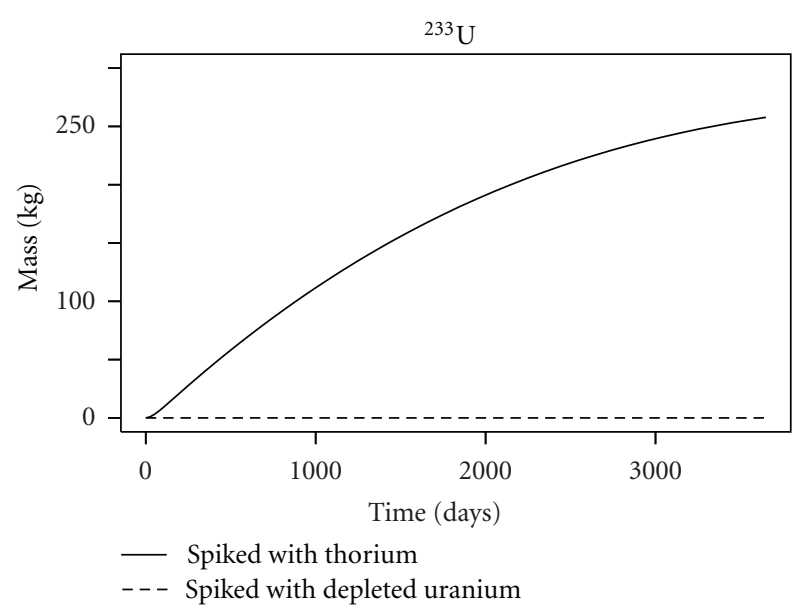

(b)

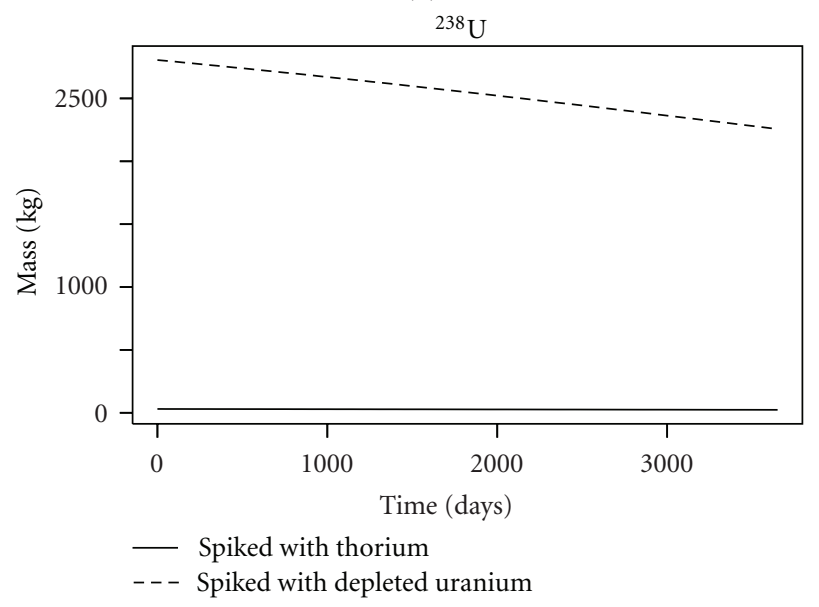

(d)

FIGURE 10: Thorium and uranium mass variation. 
shorter lifetimes with intermediate processing and addition of new plutonium. Since ${ }^{244} \mathrm{Cm}$ half-life makes 18.1 years, one can organize a controllable storage of extracted curium [32]. The Cm mass evolution in the two cases was very similar.

Neptunium is produced by $(n, \gamma)$ reaction of ${ }^{235} \mathrm{U},(n$, $2 n$ ) reaction of ${ }^{238} \mathrm{U}$, and $\alpha$-decay of ${ }^{241} \mathrm{Am}$. The most important $\mathrm{Np}$ isotope is ${ }^{237} \mathrm{~Np}$ (half-life $2.14 \times 10^{6}$ years). The decrease observed in the ${ }^{237} \mathrm{~Np}$ mass (Figure 9) is mainly due to ${ }^{238} \mathrm{~Np}$ production by neutron capture. The very low concentration of ${ }^{238} \mathrm{~Np}$ (Figure 9) is justified by the quick decay (2.117 days) to ${ }^{238} \mathrm{Pu}$ through $\beta$ decay. Once more was not observed significant difference between the mass variations for each isotope in the two cases.

The large amount of ${ }^{232} \mathrm{Th}$ in the fuel spiked with ${ }^{232} \mathrm{ThO}_{2}$ results in a high ${ }^{233} \mathrm{U}$ production $(\sim 258 \mathrm{~kg})$, as can be observed in Figure 10. That fuel regeneration potential appears with an advantage of the reprocessed fuel spiked with thorium. Figure 10 also shows the ${ }^{235} \mathrm{U}$ and ${ }^{238} \mathrm{U}$ mass variations.

\section{Conclusions}

The main conclusions indicated by the simulation presented in this work were as follow.

(i) It is noteworthy that the code does not take into account the flux from external source during the burnup, so the $k_{\text {eff }}$ and fuel results obtained are just approximations. Nevertheless, such approximated results are reasonable ones as long as the external source would not be sufficient to drive the system towards criticality, because the $k_{\text {eff }}$ values obtained were substantial low during the operation period. The initial $k_{\text {eff }}$ obtained $\left(k_{\text {eff }(\text { initial })}=\right.$ neutrons $_{\text {fission }}+$ neutrons spallation $)$ were appropriate for an ADS and the $k_{\text {eff }}$ obtained during the burnup $\left(k_{\text {eff }}=\right.$

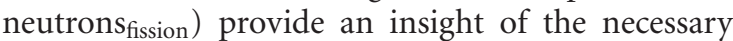
contribution of the external source on the operation period.

(ii) The insertion of reprocessed fuel in a ${ }^{232} \mathrm{ThO}_{2}$ system leads to harder neutron spectra due to the plutonium presence, facilitating the ${ }^{233} \mathrm{U}$ production. This is result of the protactinium effect reduction by hardening of the neutron spectrum.

(iii) The reprocessed fuel evolution was very similar when that fuel was spiked with thorium or depleted uranium. However, the ${ }^{233} \mathrm{U}$ production appears with an advantage of the reprocessed fuel spiked with thorium. Furthermore, the decrease in the criticality was smaller in the system spiked with thorium that allows an extension in the burnup period.

\section{References}

[1] “A Roadmap for developing ATW Technology," ANL, 99/16, 1999.

[2] S. David, A. Billebaud, M. E. Brandan et al., "Fast subcritical hybrid reactors for energy production: evolution of physical parameters and induced radiotoxicities," Nuclear Instruments and Methods in Physics Research, Section A, vol. 443, no. 2, pp. 510-530, 2000.

[3] D. G. Cacuci, "On the neutron kinetics and control of accelerator-driven systems," Nuclear Science and Engineering, vol. 148, no. 1, pp. 55-66, 2004.

[4] K. Tsujimoto, T. Sasa, K. Nishihara, H. Oigawa, and H. Takano, "Neutronics design for lead-bismuth cooled acceleratordriven system for transmutation of minor actinide," Journal of Nuclear Science and Technology, vol. 41, no. 1, pp. 21-36, 2004.

[5] B. Calgaro, B. Vezzoni, N. Cerullo, G. Forasassi, and B. Verboomen, "Wastes management through transmutation in an ADS reactor," Science and Technology of Nuclear Installations, vol. 2008, Article ID 756181, 6 pages, 2008.

[6] H. Yapici, G. Genç, and N. Demir, "A comprehensive study on neutronics of a lead-bismuth eutectic cooled acceleratordriven sub-critical system for long-lived fission product transmutation," Annals of Nuclear Energy, vol. 35, no. 7, pp. 12641273, 2008.

[7] A. A. Hamid, P. Baeten, B. de Didier, J. Heyse, P. Schuurmans, and J. Wagemans, "MYRRHA, a multipurpose hybrid research reactor for high-end applications," Nuclear Physics News, vol. 20, no. 1, pp. 24-28, 2010.

[8] K. Furukawa et al., "The combined system of accelerator molten salt breeder (AMSB) and molten salt converter reactor (MSCR)," in Proceedings of the Japan-US Seminar on Thorium Fuel Reactors, Naora, Japan, 1982.

[9] C. D. Bowman, E. D. Arthur, P. W. Lisowski et al., "Nuclear energy generation and waste transmutation using an accelerator-driven intense thermal neutron source," Nuclear Inst. and Methods in Physics Research, A, vol. 320, no. 1-2, pp. 336367, 1992.

[10] C. D. Bowman, "Accelerator-driven systems for nuclear waste transmutation," Annual Review of Nuclear and Particle Science, vol. 48, no. 1, pp. 505-556, 1998.

[11] F. Carminati et al., "An energy amplifier for cleaner and inexhaustible nuclear energy production driven by a particle beam accelerator,” CERN/AT/93-47 (ET), 1992.

[12] C. Rubbia et al., "Conceptual design of a fast neutron operated high power energy amplifier," CERN/AT/95-44 (ET), 1995.

[13] W. Lewis, Report AECL-968, 1952.

[14] A. Araújo, C. Pereira, M. A. F. Veloso, A. L. Costa, and H. M. Dalle, "Flux and dose rate evaluation of iter system using MCNP5," Brazilian Journal of Physics, vol. 40, no. 1, pp. 58-62, 2010.

[15] G. P. Barros, C. Pereira, M. A. Veloso, A. L. Costa, and P. A. Reis, "Neutron production evaluation from a ADS target utilizing the MCNPX 2.6.0 code," Brazilian Journal of Physics, vol. 40, no. 4, pp. 414-418, 2010.

[16] C. Velasquez et al., "Axial neutron flux evaluation in a tokamak system: a possible transmution blanketposition for a fusionfission transmutation system," Brazilian Journal of Physics. In press.

[17] The European Technical Working Group an ADS, "A European Roadmap for Developing Accelerator Driven System (ADS) for Nuclear Waste Incineration," 2001.

[18] "Roadmao for developing Accelerator Transmutation of Waste (ATW) Technology," Tech. Rep. DOE/RW0-519, US Department of Energy.

[19] Ismail, P. H. Liem, N. Takaki, and H. Sekimoto, "Performance of natural uranium- and thorium-fueled fast breeder reactors (FBRs) for ${ }^{233} \mathrm{U}$ fissile production," Progress in Nuclear Energy, vol. 50, no. 2-6, pp. 290-294, 2008. 
[20] D. Pelowitz, Ed., “MCNPX User’s Manual,” Version 2.6.0., Los Alamos National Security, 2008.

[21] D. Warin, "Status of the French research program for actinides and fission products partitioning and transmutation," in Proceedings of the GLOBAL Forum, Tsukuba, Japan, 2005.

[22] M. Miguirtchian et al., "GANEX: adaptation of the DIAMEXSANEX Process for the group Actinide separation," in Proceedings of the Advanced Nuclear Fuel Cycles and Systems (GLOBAL '07), Boise, Idaho, USA, 2007.

[23] D. Warin, "Future nuclear fuel cycles: prospect and challenges for actinide recycling," Materials Science and Engineering, vol. 9, pp. 1-6, 2010.

[24] J. Hendricks et al., "MCNPX 2.6.0 Extensions," Los Alamos National Laboratory, LA-UR-08-2216, 2008.

[25] H. Nifenecker, S. David, J. M. Loiseaux, and O. Meplan, "Basics of accelerator driven subcritical reactors," Nuclear Instruments and Methods in Physics Research, Section A, vol. 463, no. 3, pp. 428-467, 2001.

[26] H. Nifenecker, S. David, J. M. Loiseaux, and A. Giorni, "Hybrid nuclear reactors," Progress in Particle and Nuclear Physics, vol. 43, pp. 683-827, 1999.

[27] ORIGEN2, “User's Manual," ORNL/TM-7175, 1980.

[28] S. Cota and C. Pereira, "Neutronic evaluation of the nonproliferating reprocessed nuclear fuels in pressurized water reactors," Annals of Nuclear Energy, vol. 24, no. 10, pp. 829834, 1997.

[29] A. Shelley, H. Akie, H. Takano, and H. Sekimoto, "Radiotoxicity hazard of $\mathrm{U}$-free $\mathrm{PuO}_{2}+\mathrm{ZrO}_{2}$ and $\mathrm{PuO}_{2}+\mathrm{ThO}_{2}$ spent fuels in LWR," Progress in Nuclear Energy, vol. 37, no. 1-4, pp. 377$382,2001$.

[30] "Production of minor actinides in thermal nuclear reactors and nonproliferation," 2011, http://www.partnershipforglobalsecurity.org/Documents/actinides_report1_eng.pdf.

[31] "Transmutation of Americium and Curium: review of solutions and impacts," 2011, http://www.oecd-nea.org/trw/docs/ mol98/session4/SIVpaper1.pdf.

[32] "Conditions of Plutonium, Americium and Curium transmutation in nuclear facilities," 2011, http://www.oecd-nea.org/ pt/docs/iem/madrid00/Proceedings/Paper65.pdf. 

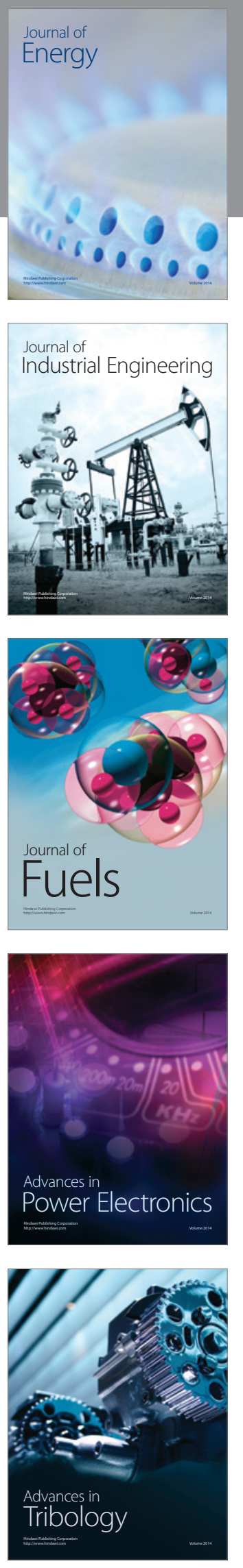
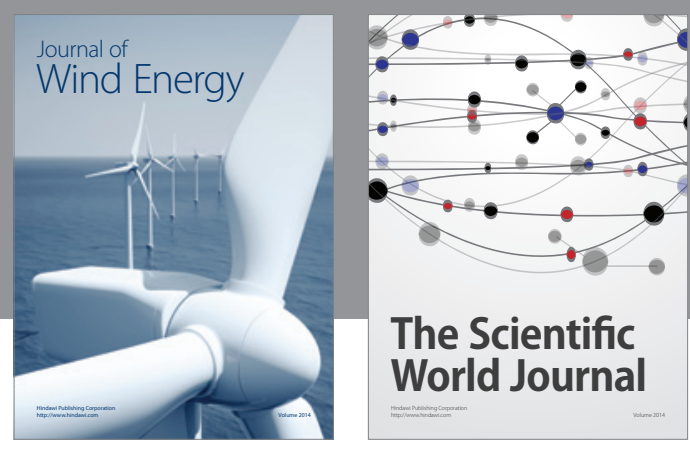

The Scientific World Journal

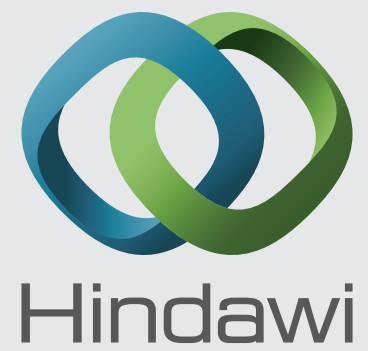

Submit your manuscripts at http://www.hindawi.com
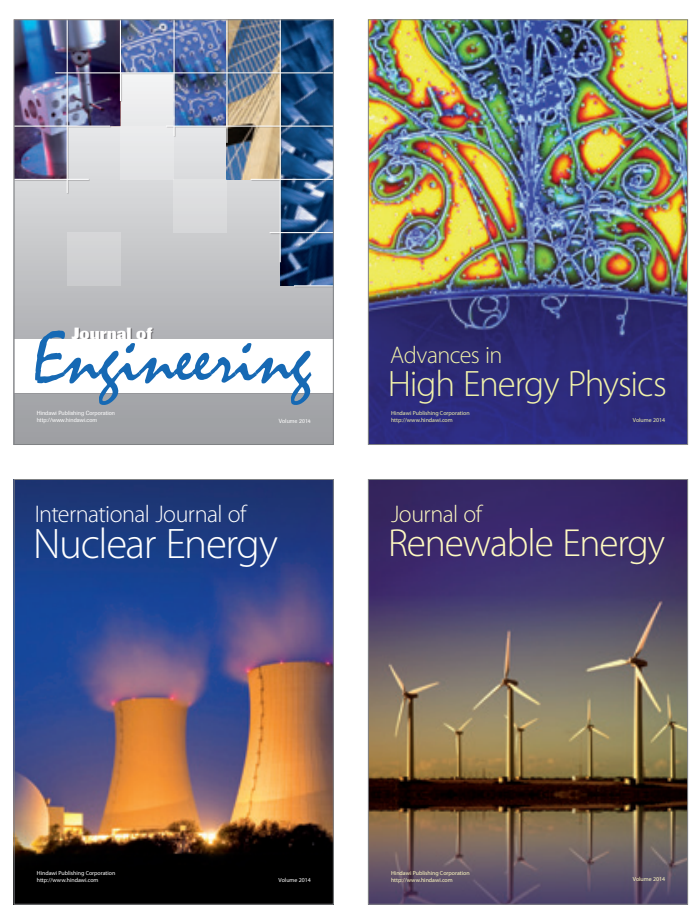

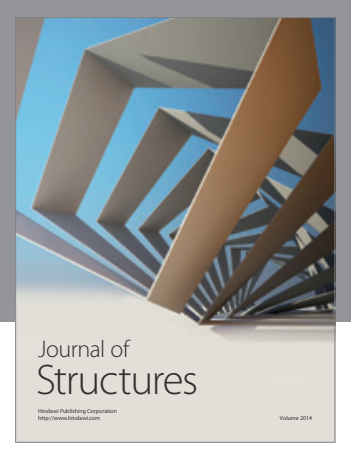

Rotating
Mechinery
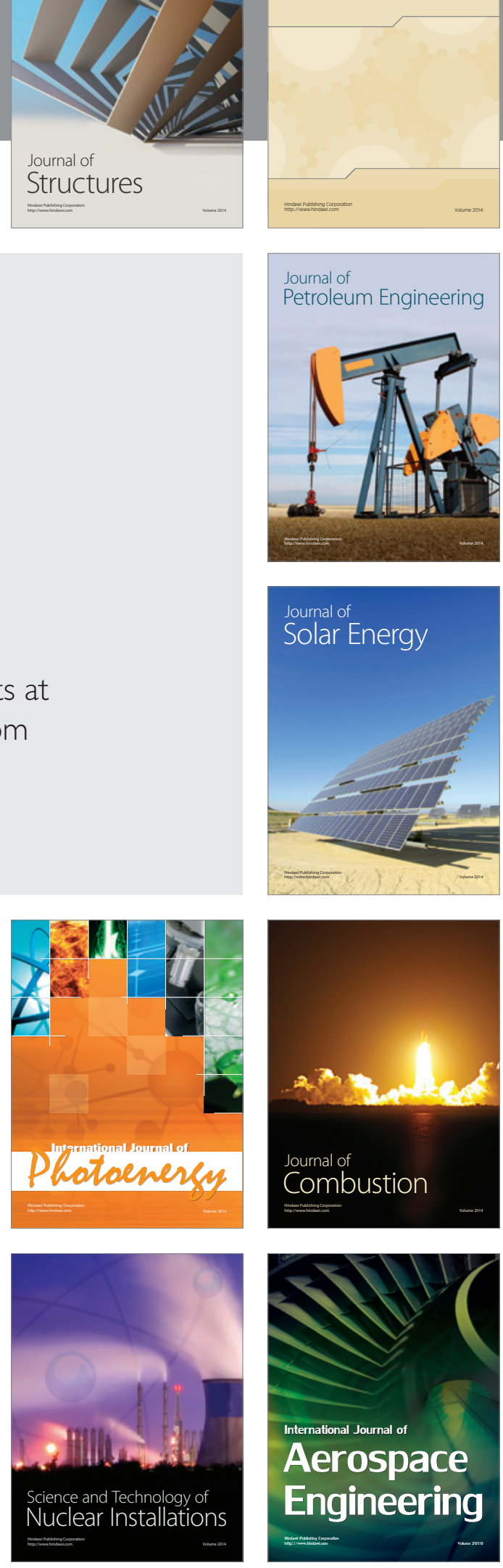